\title{
SUPPLY CHAIN MANAGEMENT MATURITY ASSESSMENT: CHALLENGES OF THE ENTERPRISES IN SERBIA
}

\author{
Marija RADOSAVLJEVIC ${ }^{1}$, Nada BARAC ${ }^{2}$, Vesna JANKOVIC-MILIC ${ }^{3}$, \\ Aleksandra ANDJELKOVIC ${ }^{4}$
}

\author{
${ }^{1}$ Willamette University, Atkinson Graduate School of Management, \\ 900 State Street, Salem, Oregon, USA \\ 1,2,3,4 Faculty of Economics, University of Nis, \\ Trg Kralja Aleksandra Ujedinitelja 11, Nis, Serbia \\ E-mails: ${ }^{1}$ marijaandjelkovic2003@yahoo.com, \\ marija.andjelkovic@eknfak.ni.ac.rs (correspondingauthor); \\ 2nada.barac@eknfak.ni.ac.rs; ${ }^{3}$ vesna.jankovic@eknfak.ni.ac.rs; \\ 4aleksandra_caka@yahoo.com
}

Received 09 January 2015; accepted 15 May 2016

\begin{abstract}
Nowadays competition has been spread to supply chains, instead of individual enterprises. Therefore, beside evaluation of enterprise's capabilities to manage business processes, it is important to assess capabilities for business process management at supply chain level. The purpose of the research presented in this paper is to point out the necessity of supply chain management maturity in implementation of best practice. Research methodology is based on supply chain management maturity models. Application of the Delphi method enabled usage of maturity model, adapted to the enterprises in Serbia. The value of the research precedes from unique combination of best practice elements for the assessment of supply chain management maturity level. The research results show that best practice elements are not very popular in the enterprises in Serbia. All enterprises are at the second and third maturity level. Bearing in mind that everything has to be improved continually, maturity models, proposed by different authors can be further developed by including certain statistical tools. The original contribution of this paper and its practical implication refer to including statistical tools, hierarchical cluster analysis and correlation, into maturity analysis, thus enabling creation of framework as a road-map for the improvement of supply chain management maturity.
\end{abstract}

Keywords: process management, supply chain, maturity, best practice, correlation analysis, cluster analysis.

JEL Classification: M11, M21, C10.

\section{Introduction}

Process-oriented organization, which observes the entire enterprise as a complex process, facilitates response to customers' requirements and maximisation of added value. At the same time, it increases reliability and speed of response to changes in the environment. Enterprise management is accomplished through process management, as 
continual process of monitoring, measuring and analyzing process performances, and, based on that, through process improvements. Some of process orientation benefits are: identification of "process owner" who is responsible for the process from start to finish, avoiding the traditional fragmentation of responsibility, fulfilment of final users' requirements (assuming that each process has a user), better communication and understanding of the requirements (by establishing the limits of the process), lower suboptimization risk, lower cost and shorter time of process realization.

Due to the fact that benefits from process orientation are significant, at the end of the last and especially at the beginning of the twenty-first century, new perspectives of process management have been opened and great number of models, describing process management maturity, appeared (Zairi, Ahmed 1999; Humphrey 1988; Gulledge, Sommer 2002; Maull et al. 2003; Fisher 2004; Hung 2006; Curtis, Alden 2007; Hammer 2007; Rosemann, De Bruin 2005; Van Looy et al. 2011; Rosemann, Vom Brocke 2015; Lindemulder 2015). Most of the introduced process maturity models are based on "staged sequence of levels" (Röglinger et al. 2012) and as such are very similar to each other (Andjelkovic Pesic 2009). If slight differences between them are neglected, all business process maturity models describe an evolutionary improvement path that leads an enterprise from the state of immaturity, with inconsistent activities and processes, to the state of highest maturity, with disciplined activities and processes. In this sense, it may be said that business process maturity models incorporate levels of maturity that are associated with the severity of process impact, the ability to monitor and control them and the possibility to influence their improvement. One of the important characteristics of those models is possibility to point to the critical aspects of business process over time. Beside authors who have introduced or recommended certain models for maturity measurement, there are, also, a lot of them who have used those models in order to identify maturity level of business process management (Ambastha, Momaya 2004; Sommerville, Ransom 2005; Wu et al. 2006; Lee et al. 2007; Neubauer 2009).

However, the most of process management models refer to the enterprise level (Janjic et al. 2015). Bearing in mind that in modern, global economy competition mostly takes place between supply chains instead of individual enterprises, it is preferably to identify, measure and improve maturity at the supply chain level. Realizing the importance of supply chain maturity, certain authors have formulated and implemented models they considered appropriate (Lockamy, McCormack 2004; Jaklic et al. 2006; Vaidyanathan, Howell 2007; Netland et al. 2007; McCormack et al. 2008).

The usefulness of the formulated models for supply chain maturity assessment has been confirmed in practice. For example, Bowersox et al. (2000) claim that supply chain performance may be improved by increasing supply chain maturity, if supply chain maturity is observed as the level of adoption of modern collaborative and integrative supply chain practices. Collaboration and integration are, also, in the basis of conclusions of Fawcett and Magnan (2002), who claim that collaboration and integrative mechanisms for enhancing coordination are reasons for higher maturity level of supply chains. Some authors (Lockamy, McCormack 2004) have been trying to identify the relationship between supply chain maturity and certain variables. They used linear regression analysis, 
which confirmed that supply chain management process performance is strongly related to its maturity. Precisely, the results especially indicate maturity effects on performance measures such as cycle times and inventory level. The research conducted in Brazil has indicated positive statistical relationship between supply chain maturity and performance, with the note that the impact of deliver process maturity is greater compared to the other supply chain processes (McCormack et al. 2008). Arzu Akyuz and Erman Erkan who have been studding other authors' research results concluded that there is direct correlation between maturity and supply chain performance, but also that "literature is still in search of maturity models and roadmaps" (2010: 5148). The results from different continents, cultures and industries included in global investigation concerning maturity, "confirm the applicability of business process orientation concepts to a wide range of companies" (McCormack et al. 2009: 812) and effects the maturity has on performances, since business process orientation concept may be extended to the supply chain level.

The following pages will demystify supply chain management maturity, and point out its similarities with business process management maturity. This is followed by the analysis of few supply chain management maturity models and the presentation of the hypotheses and the model for supply chain management maturity assessment, adapted for the application in the enterprises in Serbia. Based on the data gained through empirical research and application of certain statistical tools, such as ANOVA, correlation and cluster analysis, the last part of the paper includes discussion and assessment of supply chain management maturity level according to the application of the best practices. The conclusions section summarizes the positive and negative observations and indicates the topics for the future research.

\section{Process vs. supply chain maturity: phases and characteristics}

According to de Bruin's model (2007), the level of maturity is determined by the quality and presence of certain factors. Based on the Delphi study conducted by the same author, as the most significant factors are identified: Strategic alignment, Governance, Methods, Information technology, People and Culture. The extent to which those elements are developed and present in an enterprise determines the maturity level. Precisely, the enterprise may be in one of the following states (McCormack et al. 2009): silos (enlightenment), tactical integration (stabilization), process orientation (standardization), optimized enterprise (systematization) and intelligent network (optimization).

If it is accepted that "the supply chain includes all enterprises that directly or indirectly contribute to the achievement of customer requirements" (Chopra, Meindl 2009: 5), then it may be said that processes within each enterprise are involved in meeting the demand of customers (internal, within the supply chain, or external, outside the supply chain). Therefore, business processes of every enterprise, which is a member of supply chain, are part of larger processes that take place within the chain. Today, in highly competitive environment, global supply chains are an inexhaustible source of competitive advantage for enterprises they consist of. Therefore, it is very important that business process 
maturity of an enterprise is followed by maturity of supply chain that it belongs or vice versa. For that reason, concerning process management focus becomes wider, including supply chain maturity, and not only enterprise maturity. Those two levels of maturity observation are presented below, through the phases they involve.

1. Managers' awareness about the importance of process approach is necessary to embark the enterprise on the road to achieve maturity. Top management awareness and support are important, but process identification and performance measurement assumes spreading this awareness through the enterprise. Key processes are defined and documented, but the inconsistency that characterizes this phase is main constraint for the next step towards business excellence (Maull et al. 2003). There are no defined process measures and practices that would be applied systematically. Therefore it might be said that enterprises are in the state called silo. At supply chain level there are also no structured and standardized practices. Since process orientation is missing, horizontal supply chain processes are not identified and supply chain management costs are high (Lockamy, McCormack 2004). For these reasons, this level is usually called ad hoc level. The only reason why supply chain or enterprise in this state may provide certain results is effort of individuals, which usually is not long lasting. Leaving this state involves initiating some changes.

2. Implementation of process approach in the enterprises actually begins at the second maturity level, because, beside key processes, other business processes are identified, their inputs and outputs determined, as well as the methods and procedures for their realization. Higher process maturity level means higher process stability or less variation, and consequently easier prediction of the results (Huffner 2007). At this level very important is to determine managers' responsibilities, and especially identification of process owners (Palmberg 2010: 109). However, at this level, employees' training is still missing, and therefore performance measurement is only periodical and partial (Röglinger et al. 2012). Therefore, it might be said that enterprise is in the state called tactical integration. At supply chain level, basic processes that connect participants are defined and documented, which is the first step towards stabilization. Due to the fact that processes are identified, this level is marked as defined. Process identification necessary for overcoming functional silos, but supply chain management costs are still high (Lockamy, McCormack 2004). In this state supply chain performances are more predictable and customer satisfaction higher, but still not enough or far from the values that can be reached.

3. For proper integration, it is necessary to provide standardization and synchronization, in order to implement best practices to all processes. If standards are established, not only when it is about procedures, tools and instructions, but also when it is about employees' behaviour and communication, then standardization is the introduction for the culture change process (Alibabaei et al. 2010), because peple must try to fit as much as possible (Arsanjani et al. 2015). In this phase the enterprise is in the state called process orientation, since all processes are identified. Links between supply chain partners are stronger and cooperation is based on sharing common performance and process measures and goals between the partners. Due to those facts, in this phase 
supply chain is usually called linked. Costs of supply chain management are decreasing (Lockamy, McCormack 2004) and continual improvement at process level inside all supply chain partners leads to customer satisfaction.

4. Establishment of Statistical process control is condition for providing process stability and increasing its capability. Hence, due to its implementation processes are considered as managed. At this maturity level the enterprise is viewed as a network of processes and is labelled as optimized. Standardization in form of best practices spreads over the supply chain. All partners use the same measures and management systems, which leads to integration and collaboration through the supply chain. However, even more important is the fact that suppliers and customers, as partners in supply chain, cooperate on the process basis. Actually, connections between suppliers and customers are horizontal, meaning that process is continued from the first supplier till the last customer in the supply chain, without any interruptions. Performances of supply chain processes become predictable. Supply chain management costs are significantly reduced (Lockamy, McCormack 2004) and continual improvements at supply chain level increase customer satisfaction. It may be said that at this level cooperation develops into collaboration, which means identification with the group of partners, free sharing of information, as well as great distance from enterprises outside the chain and no distance from the chain members. This further means that at this level supply chain is integrated.

5. The characteristic of the enterprise at fifth level is continual improvement through incremental and radical changes, so it may be considered as optimized. At this level, performance measurement and management is performed systematically and collected data are analysed quantitatively and qualitatively. Results of analysis are used for continuous, proactive process improvement. Therefore, optimization is provided at the enterprise level. Since processes are managed at the value chain level, the enterprises at this level are called intelligent networks. At supply chain level there is trust and mutual dependency as the glue holding the supply chain partners together (Forslund, Jonsson 2009). Process performance and reliability of the integrated supply chain are measured with the same measures and investments in improvement of the entire system are joined (Lockamy, McCormack 2004). Considering strong connections between the enterprises in supply chain, one can get the impression that single enterprise is extended to its suppliers and customers, meaning that there are no strict boundaries determining where one enterprise's activities and processes finish and some others' begin.

As it can be noticed, maturity of supply chain depends on maturity of enterprises involved into the chain, but also on their mutual alignment. In any case, process maturity is the foundation for process-oriented organization and supply chain integration since processes take the central role in it (Jaklic et al. 2006). Therefore, in order to reach higher level of supply chain maturity, enterprises which constitute it have to work as a team with activities integrated through cross-functional and cross-enterprise processes (Radosavljevic 2015). 


\section{Research framework, hypotheses and methodology}

McCormack and Johnson (2002) have explained the importance of assessment and improvement of supply chain management maturity claiming that "the supply chain management journey is a difficult one, and without a map and a compass, it is impossible". Model that describes supply chain management maturity represents kind of map or dashboard for keeping the chain at wanted course.

Some authors (Lockamy, McCormack 2004) suggested that for supply management maturity researcher may use some models for business process management maturity. This is confirmed in previous analysis of process and supply chain management maturity, which indicated that those two concepts are connected and conditioned (Radosavljevic 2015). In order to choose the model for supply chain management maturity assessment and improvement that would be applicable for the enterprises in Serbia, few existing models have been analysed. They are: BPMMM formulated by Rosemann and de Bruin (2005), SCMAT model proposed by Netland et al. (2007), S(CM) ${ }^{2}$ created by Garcia (2008) and SCPM3 offered by de Oliveira et al. (2011).

Rosemann and de Bruin have proposed a methodology and outlined the main phases of development of maturity management model, which can be applied in any enterprise. The methodology they have proposed is based on Business process management and Knowledge management (De Bruin et al. 2005). According to those authors, success factors of business process management are: Strategic alignment, Governance, People, Methods, Culture, and Information technology. On the other hand, those factors are influenced by knowledge management capability, including: lessons learned, knowledge documents, data, and expertise. This model is embedded into a great number of maturity models at the enterprise level, but may be also used as framework for the assessment and improvement at supply chain management maturity level.

SCMAT model represents some kind of test, which is actually its full name - Supply chain management assessment test. In order to assess maturity, Netland et al. (2007) suggested 50 best practices that are evaluated regarding maturity, which they have separated into the seven categories: Strategy, Control, Processes, Resources, Materials, Information, and Organization. As one of the sources for gathering best practices they used the European Foundation for Quality Management's (EFQM) Excellence Model, which represents a framework for achieving sustainable excellence based on best practices in quality issues. In that way they have established relationship between maturity and excellence or quality management (Boskovic, Radosavljevic 2015).

$\mathrm{S}(\mathrm{CM})^{2}$ is acronym for Supply Chain Capability Maturity Model proposed by Garcia in his dissertation A capability maturity model to assess supply chain performance. In this work Garcia provides a roadmap for enterprise improvement, but also tools to support the improvements. His research is based on the Delphi method. As a result of this method certain factors stood out from the rest as the most important and they are: Suppliers, Production Systems, Inventory, Customers, Human Resources, Information Systems \& Technology, Performance measurement Systems (Garcia 2008). Those factors represent different views of the business in modern conditions. 
De Oliveira et al. tried to answer the question "What best practices are fully matured and in use at what maturity level?" (De Oliveira et al. 2011: 201). The model they have used, Supply chain process management maturity model or SCPM3, includes 90 indicators of supply chain management maturity grouped into 13 categories: Demand management and forecasting, Strategic planning team, Strategic behaviours, Procurement team, Supply network management, Production planning and scheduling, Distribution network management, Order management, Process governance, Foundation building, Responsiveness, Collaboratively integrated practices, and Customer integration.

With the arrival of foreign companies to Serbia, their managers have begun to convey the experience of supply chain management, including new techniques and management principles, from their parent companies. The intention of the authors is to point out the significance of supply chain management maturity and to present and analyse the application of the best practices in supply chain management in Serbia.

Due to the fact that enterprises from Serbia have to cooperate with the partners from other countries, especially from the European Union due to the accessing process, but also that they have to face the competition from developed countries, quantification of supply chain maturity is an important issue. Precisely, through supply chain management maturity analysis enterprises from Serbia have an opportunity to benchmark performance measurements and process improvement actions with the ones used by their present and potential partners (McCormack et al. 2008).

Benchmarking of the mentioned models is presented in the table below (Table 1). This table contains main elements of those models, indicating similarities, which will be the basis for realization of the Delphi method, in order to adapt presented models for the assessment of supply chain management maturity in Serbia.

Development of supply chain maturity management model is considered as key for creating an improvement map, which will enable enterprises from Serbia to fit better into supply chains, usually combined of enterprises from different countries. In order to change supply chain maturity management model, to be appropriate for the enterprises in Serbia, in sense that they will be able to evaluate their supply chain activities and their contribution to the supply chain they belong to, the Delphi method was used.

Usage of this method for the adaption of presented maturity models is not unusual, since some of previously mentioned models, but also, a lot of others, were transformed more or less in order to be adapted for the implementation in certain countries. Usually, this transformation was necessary when those methods were implemented inside developing countries. For example, Garcia and Giachetti (2010) used knowledge and expertise of participants in order to develop a supply chain maturity model so that Mexican enterprises could be able to evaluate supply chain operations and develop road-map for the improvement.

The Delphi survey is a group facilitation technique, based on an iterative multistage process, with the objective to transform opinion into group consensus, bearing in mind that individuals that will be affected directly by the decision to be made, "are more likely to become involved in the Delphi process" (Hasson et al. 2000: 1010). 
In this case, Delphi method realization involved 92 experts in supply chain management field. After the consensus was achieved in over $90 \%$ of the items, they were included into the questionnaire (Landeta 2006).

Based on the responses of the participants and achieved consensus, as well as, bearing in mind specificities of doing business in Serbia, the authors propose modified model, named Supply chain maturity development model - SCDM2. The name of this model should indicate that supply chain maturity has to be developed during time and not reach in short term, but also that it is intended for enterprises in Serbia, as the country that is still in transition or developing country. The modified model is show with other maturity models in Table 1.

Table 1. Benchmarking of supply chain management maturity models

\begin{tabular}{|c|c|c|c|c|}
\hline BPMMM & $\mathrm{S}(\mathrm{CM})^{2}$ & SCPM3 & SCMAT & SCDM2 \\
\hline $\begin{array}{l}\text { Strategic } \\
\text { alignment }\end{array}$ & Inventory & Strategic planning team & Strategy & $\begin{array}{l}\text { Strategy } \\
\text { and planning }\end{array}$ \\
\hline Governance & Human resources & Strategic behaviors & Organization & $\begin{array}{l}\text { Leadership } \\
\text { and culture }\end{array}$ \\
\hline People & Suppliers & Procurement team & Resources & Human resources \\
\hline Methods & Production systems & $\begin{array}{l}\text { Demand management and } \\
\text { forecasting }\end{array}$ & Materials & $\begin{array}{l}\text { Suppliers } \\
\text { and inventory }\end{array}$ \\
\hline Culture & Customers & $\begin{array}{l}\text { Supply network } \\
\text { management }\end{array}$ & Information & Processes \\
\hline \multirow[t]{8}{*}{$\begin{array}{l}\text { Information } \\
\text { technology }\end{array}$} & $\begin{array}{l}\text { Information systems \& } \\
\text { technology }\end{array}$ & $\begin{array}{l}\text { Production planning and } \\
\text { scheduling }\end{array}$ & Control & Customers \\
\hline & $\begin{array}{l}\text { Performance } \\
\text { measurement systems }\end{array}$ & $\begin{array}{l}\text { Distribution network } \\
\text { management }\end{array}$ & Processes & $\begin{array}{l}\text { Information } \\
\text { technology }\end{array}$ \\
\hline & & Order management & & $\begin{array}{l}\text { Performance } \\
\text { measurement }\end{array}$ \\
\hline & & Process governance & & \\
\hline & & Foundation building & & \\
\hline & & Responsiveness & & \\
\hline & & $\begin{array}{l}\text { Collaboratively integrated } \\
\text { practices }\end{array}$ & & \\
\hline & & Customer integration & & \\
\hline
\end{tabular}

In order to test proposed model, empirical research has been conducted. Questionnaire was sent to 600 randomly chosen enterprises (who indicated that they belong to certain supply chain during pre-research), and 132 completed samples were returned, which means that response rate is $22 \%$.

The most of the enterprises that were not willing to participate in this research claimed that they are not familiar with maturity concept and supply chain best practices or that they have not adopted process orientation, at all. Since process orientation is condition 
sine qua non not just for development, but also for sustainability of enterprises in XXI century, there is a doubt that one of the reasons for Serbian enterprises lagging for foreign enterprises is precisely the lack of process orientation.

The questions used in this model are mostly based on best practices, where "best practices describe the state-of-the-art of how to perform a business" (Van Landeghem, Persoons 2001: 254). Best practices were used with purpose to provide benchmarking. Precisely, this kind of benchmarking allows enterprises to identify the extent to which best practices are used, as well as to identify their effectiveness based on the key metrics (Netland et al. 2007). Best practices used in the researches of the mentioned authors were collected and presented to the managers during pre-research phase. Based on their judgement on usefulness of those best practices in the environment they operate in, as well as based on capabilities for the application of those best practices, 80 issues were chosen and grouped into 8 categories (as it was shown in Table 1, under the SCDM2 model).

Initial assumption of this model is causality, meaning that the elements included in model influence each other, but also have influence on performances of the enterprises in supply chain. The leading idea is that implementation of those best practices should provide improvement in four main competitiveness dimensions: flexibility, time, quality and cost.

First hypothesis concerns differences between maturity levels in application of the best practices. It is formulated in the following way: There are no differences between maturity levels in application of best practices, meaning that all practices are equally represented. The second hypothesis includes connection between best practices and is formulated as: Best practices applied in the enterprises are mutually connected, meaning that there is high correlation between implemented best practices. For testing of those hypotheses, ANOVA and correlation analysis (Dasic 2012) as statistical tools have been used. For creating framework for the supply chain maturity improvement, Dendrogram, as a result of hierarchical cluster analysis, has been used.

Table 2. The explanation of grades in maturity assessment process

\begin{tabular}{cc}
\hline Grades & Explanation \\
\hline 1 & Never or does not exist \\
\hline 2 & Sometimes or to some extent \\
\hline 3 & Frequently or partly exist \\
\hline 4 & Mostly or often exist \\
\hline 5 & Always or definitely exist \\
\hline
\end{tabular}

Source: Netland et al. 2007

For grading of the enterprises in the sample five-point Likert scale has been used (the explanation of the grades is given in Table 2). Those grades should indicate to which extent the enterprises in certain supply chain use previously identified best practices. 


\section{Maturity assessment: research results and discussion}

Analysis of variance has been used to provide the answer whether there are differences between the observed groups of best practices ( 8 groups, presented in Table 1, under the SCDM2 model). ANOVA has shown that first hypothesis should be rejected (significance is less than 0.0001), meaning that there are differences between maturity levels in application of best practices grouped in eight categories (Table 3).

Table 3. ANOVA results for the groups

\begin{tabular}{cccccc}
\hline & Sum of squares & df & Mean square & F & Sig. \\
\hline Between groups & 1739.136 & 7 & 248.448 & 6.779 & .000 \\
\hline Within groups & 38407.818 & 1048 & 36.649 & & \\
\hline Total & 40146.955 & 1055 & & & \\
\hline
\end{tabular}

Since there is difference between maturity levels of the observed groups of best practices, in the next step the sum of the scores for those groups has been calculated in order to determine maturity level for each of eight groups. Maturity levels for groups are based on the sum of scores of all entities. Minimal possible score for a group is 1320, while maximal possible score is $6600^{1}$. The limits between maturity levels are determined based on the interval mean. Therefore, the lowest, first level can have maximal score 1980, the second 3300, the third 4620, the fourth 5940 and the fifth 6600 . Since minimal total score for the groups in the sample is 2964 , and maximal 3442 , it may be concluded that observed groups are positioned at the second and third level (Table 4).

Table 4. Centroids by maturity levels for the best practice groups

\begin{tabular}{cccccc}
\hline Maturity levels for the best practice groups & Centroid & $\mathrm{N}$ & Std. deviation & Minimum & Maximum \\
\hline 2 & 3110.6000 & 5 & 139.70433 & 2964.00 & 3258.00 \\
\hline 3 & 3377.6667 & 3 & 60.86323 & 3321.00 & 3442.00 \\
\hline Total & 3210.7500 & 8 & 176.96307 & 2964.00 & 3442.00 \\
\hline
\end{tabular}

In order to identify whether application of different groups of best practices is mutually connected, correlation analysis has been performed. This analysis in the most cases confirms the second hypothesis that different groups of best practices are mutually connected, meaning that there is high correlation between implemented best practices. The highest correlation has been observed between the following groups: Human resources and Suppliers and inventory (0.575), Human resources and Leadership and culture (0.5687), Human resources and Strategy and planning (0.506), Leadership and culture and Suppliers and inventory (0.481), Processes and Customers (0.330), Strategy and planning and Customers $(0.273)$.

\footnotetext{
${ }^{1}$ Bearing in mind that the sample included 132 enterprises, that there are 8 groups of questions addressing to each group of the best practices, that each group included 10 questions and that the minimal grade is 1 (Table 1) the minimal possible score for a group is calculated as a product of 132 enterprises, 10 questions and grade 1 , which is equal 1320. The same was done for the maximal possible score, which was calculated as a product of 132 enterprises, 10 questions and grade 5.
} 
With the same purpose, in order to determine connection between the groups, grouping of the observed groups has been realized. Cluster analysis is the method of multivariate analysis and serves for the classification of objects according to their characteristics (Everitt, Hothorn 2011). Apropriate method of clusterization, which has been implemented, is hierarchical cluster analysis. Hierarchical procedures involve the construction of a hierarchical structure resembling a tree (Kothari 2003). This method, in contrast to the k-means cluster analysis, does not require a large sample. As a criterion for linking the observed groups, Between groups linkage has been used, and as a measure of the distance, Squared Euclidean distance.

As a result of hierarchical cluster analysis and correlation coefficients, framework for the improvement of supply chain maturity has been created (Fig. 1).

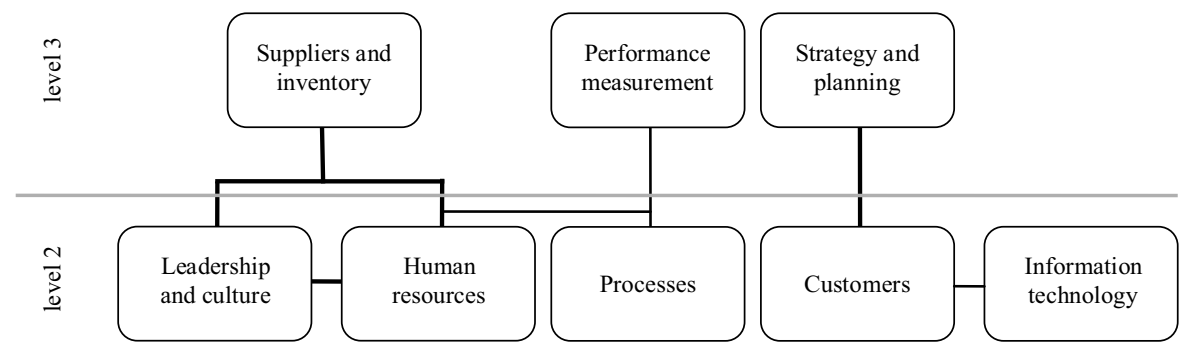

Fig. 1. Supply chain management maturity improvement framework

Gray line in this figure divides two maturity levels, the second and the third, showing that Suppliers and inventory, Human resources, Strategy and planning, Processes and Information technology are at the second maturity level, while Leadership and culture, Performance measurement and Customers are at the third maturity level. The thickness of the lines that connect mentioned groups of the best practice should indicate the strength of the relationship between them (thicker line means stronger connection, based on correlation coefficients).

Similarly like for the groups of best practices, maturity score for the enterprises has been calculated by summing all variables (groups) for each one of the 132 cases of the sample. By using the same principle, minimal possible score for an enterprise is 80 , while maximal possible score is 400 . Total scores for the enterprises in this research is between 143 and 265. The limit for the lowest, first level is 120, for the second 200, for the third 280, for the fourth 360 and for the fifth 400. Based on the results presented in Table 5, it may be concluded that observed enterprises are positioned at the second and third level (Table 5), and that there are no enterprises at the first, fourth and fifth maturity level.

Table 5. Centroids by maturity levels for the enterprises

\begin{tabular}{cccccc}
\hline Maturity levels for the enterprises & Centroid & $\mathrm{N}$ & Std. deviation & Minimum & Maximum \\
\hline 2 & 178.1500 & 80 & 14.20474 & 143.00 & 199.00 \\
\hline 3 & 219.8846 & 52 & 17.49023 & 201.00 & 265.00 \\
\hline Total & 194.5909 & 132 & 25.68659 & 143.00 & 265.00 \\
\hline
\end{tabular}


In order to identify which groups of best practices are leading and lagging for the enterprises at the second and the third level, the average total score for the specific maturity levels of the enterprises have been calculated. This, actually, is analysis of those two groups of enterprises (at the second and at the third maturity level) for each of eight groups of best practices (Table 6). The first observation is that average total score for all best practice groups is higher for the enterprises at the third maturity level, which is expected.

Table 6. Average values of the best practices groups for the enterprises by maturity levels

\begin{tabular}{|c|c|c|c|c|c|c|c|c|c|}
\hline & 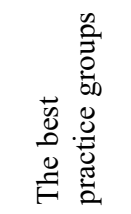 & 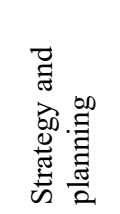 & 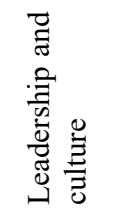 & 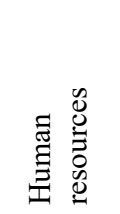 & 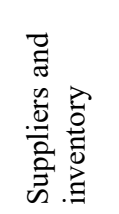 & $\begin{array}{l}0 \\
0 \\
0 \\
0 \\
0 \\
0 \\
0\end{array}$ & 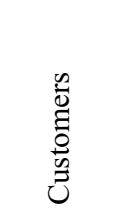 & 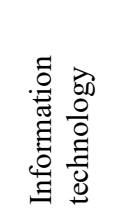 & 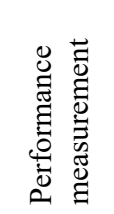 \\
\hline \multirow{4}{*}{$\begin{array}{c}\text { Maturity } \\
\text { levels }\end{array}$} & Mean & 20.6000 & 23.2625 & 19.1375 & 19.2875 & 23.2500 & 24.1500 & 23.8000 & 24.6625 \\
\hline & $\mathrm{N}$ & 80 & 80 & 80 & 80 & 80 & 80 & 80 & 80 \\
\hline & Mean & 28.0962 & 30.4038 & 27.8462 & 27.3269 & 26.8846 & 26.7115 & 25.7500 & 26.8654 \\
\hline & $\mathrm{N}$ & 52 & 52 & 52 & 52 & 52 & 52 & 52 & 52 \\
\hline \multirow{2}{*}{ Total } & Mean & 23.5530 & 26.0758 & 22.5682 & 22.4545 & 24.6818 & 25.1591 & 24.5682 & 25.5303 \\
\hline & $\mathrm{N}$ & 132 & 132 & 132 & 132 & 132 & 132 & 132 & 132 \\
\hline
\end{tabular}

The observation, which is more important, is that the lowest average total score for the enterprises at the second maturity level have Human resources and Suppliers and inventory, followed by Strategy and planning, while the lowest average values for the enterprises at the third maturity level have Information technology, Customers and Performance measurement. This means that the main limitations for reaching the third maturity level, for the enterprises at the second level, are the best practices under Human resources, Suppliers and inventory and Strategy and planning. On the other hand, for the enterprises at the third level, the main limitation for reaching the fourth maturity level are the best practices that concern Information technology, Customers and Performance measurement.

\section{Conclusions}

The goal of continual improvement under maturity models is transferring the philosophy of process improvement from process level to an enterprise level and furthermore to supply chain level. Though maturity models are useful for the improvement of managing and achieving results, as their limitation might be considered the fact that they do not offer a methodological approach the managers could use as a guide for achieving higher maturity levels. However, when used along with the statistical tools, such as correlation analysis and hierarchical cluster analysis, maturity models may be used for creating a framework or some kind of road-map for overcoming the limitations and 
for using connections between the observed elements. In this case, created framework shows the level of maturity in using the best practices in supply chain management, on one hand, and describes the relationships between those best practices, on the other hand. Also, this framework facilitates identification of bottlenecks or limitations for further improvement of supply chain management maturity. This qualifies it as valuable framework for corporate leadership.

The positive observation is the fact that there is positive correlation between the observed groups of the best practices, meaning that implementation of one may withdraw the implementation of other best practices. On the other hand, negative observation is the fact that those connected groups of the best practices are not at the same maturity level, meaning that those that are at the lower maturity level may be limitation for reaching higher maturity level. Anyway, the conclusion is that the most of the enterprises in Serbia, according to the implementation of supply chain best practices, are the second and third maturity level. This is not disappointing result, but certainly is the result that should be improved in the future.

In that sense, the research presented in this paper may be used by the managers of the enterprises from Serbia to evaluate their own supply chain operations and develop improvement plans or frameworks. This could be a first step to make them suitable partners for the enterprises from developed countries and facilitate their inclusion into global supply chains. Practical implications of this paper refer to including statistical tools, precisely hierarchical cluster analysis and correlation analysis, into maturity analysis and creating framework for the improvement of supply chain management maturity, through marking the best practices that represent kind of bottlenecks.

One of the topics for the future research may be an analysis of the influence of foreign companies, which increasingly conquer developing countries' markets, in terms of expanding the application of best practices in supply chain management. Also, it would be interesting to investigate and analyze if there is connection and dependency between maturity of the enterprises in the sense of implementing the best practices in supply chain management and the type of industry that enterprises belong. Finally, it would be useful if the same research is performed in other developing countries, which could confirm or demand the conclusions presented in this paper.

\section{Acknowledgements}

We would like to thank American Councils for International Education, which is in charge for administration of Junior Faculty Development Program (JFDP), a program of Bureau of Educational and Cultural Affairs of the United States Department of State, for supporting stay of Marija Radosavljevic in the United States (Oregon, Salem, Willamette University: Atkinson Graduate School of Management), during which the main research for the paper has been done. Also, we would like to thank Ministry of Education and Science of the Republic of Serbia for supporting this research. 


\section{References}

Alibabaei, A.; Aghdasi, M.; Zarei, B.; Stewart, G. 2010. The role of culture in business process management initiatives, Australian Journal of Basic and Applied Sciences 7(4): 2143-2154.

Ambastha, A.; Momaya, K. 2004. Competitiveness of firms: review of theory, frameworks, and models, Singapore Management Review 26(1): 45-61.

Andjelkovic Pesic, M. 2009. Business process management maturity model and Six Sigma: an integrated approach for easier networking [online], [cited 25 August 2012]. International Conference on Economics and Management of Networks (EMNet 2009), 3-5 September 2009, Sarajevo, Bosnia and Herzegovina. Available from Internet: https:/emnet.univie.ac.at/uploads/ media/Andjelkovic-Pesic_01.pdf

Arsanjani, A.; Bharade, N.; Borgenstrand, M.; Schume, P.; Wood, K. J.; Zheltonogov, V. 2015. Business process management design guide using IBM business process manager [online], [cited 11 January 2016], International Business Machines Corporation. Available from Internet: http:// www.redbooks.ibm.com/abstracts/sg248282.html

Arzu Akyuz, G.; Erman Erkan, T. 2010. Supply chain performance measurement: a literature review, International Journal of Production Research 48(17): 5137-5155.

http://dx.doi.org/10.1080/00207540903089536

Boskovic, G.; Radosavljevic, M. 2015. Analysis of factors and effects of product design quality, Economic Themes 53(4): 495-513. http://dx.doi.org/10.1515/ethemes-2015-0028

Bowersox, D. J.; Closs, D. J.; Stank, T. P. 2000. Ten mega trends that will revolutionize supply chain logistics, Journal of Business Logistics 21(2): 1-16.

Chopra, S.; Meindl, P. 2009. Supply chain management - strategy, planning and operations. New York: Prentice Hall.

Curtis, B.; Alden, J. 2007. The business process maturity model: what, why and how, A BPTrends Column 2: 1-4.

Dasic, P. 2012. Application of polynomial regression models for approximation of time series, Journal of Economic and Management Based on New Technologies 1(2): 81-160.

De Bruin, T.; Freeze, R.; Kaulkarni, U.; Rosemann, M. 2005. Understanding the main phases of developing a maturity assessment model, in $16^{\text {th }}$ Australasian Conference on Information Systems (ACIS 2005), 30 November - 2 December, 2005, Sydney, Australia.

De Bruin, T. 2007. Insights into the evolution of BPM in organizations, in 18th Australasian Conference on Information Systems (ACIS 2007), 5-7 December, 2007, Toowoomba, Australia.

De Oliveira, M. P. V.; Ladeira, M. B.; McCormack, K. P. 2011. The supply chain process management maturity model - SCPM3, Chapter 13 in D. Önkal, E. Aktas (Eds.). Supply chain management-pathways for research and practice, Rijeka, Croatia: InTech.

http://dx.doi.org/10.5772/18961

Everitt, B.; Hothorn, T. 2011. An introduction to applied multivariate analysis with R. New York, NY: Springer. http://dx.doi.org/10.1007/978-1-4419-9650-3

Fawcett, S. E.; Magnan, G. M. 2002. The rhetoric and reality of supply chain integration, International Journal of Physical Distribution and Logistics Management 32(5): 339-361.

http://dx.doi.org/10.1108/09600030210436222

Fisher, M. 2004. The business process maturity model: a practical approach for identifying opportunities for optimization, BPTrends 9: 1-7.

Forslund, H.; Jonsson, P. 2009. Obstacles to supply chain integration of the performance management process in buyer-supplier dyads: the buyers' perspective, International Journal of Operations \& Production Management 29(1): 77-95. http://dx.doi.org/10.1108/01443570910925370 
Garcia, H.; Giachetti, R. 2010. Using experts to develop a supply chain maturity model in Mexico, Supply Chain Management: An International Journal 15(6): 415-424.

Garcia, H. 2008. A capability maturity model to assess supply chain performance. Doctoral dissertation, Florida International University, Miami, Florida.

Gulledge, Jr, T. R.; Sommer, R. A. 2002. Business process management: public sector implications, Business Process Management Journal 8(4): 364-376.

http://dx.doi.org/10.1108/14637150210435017

Hammer, M. 2007. The process audit, Harvard Business Review 85(4): 1-17.

Hasson, F.; Keeney, S.; McKenna, H. 2000. Research guidelines for the Delphi survey technique, Journal of Advanced Nursing 32(4): 1008-1015.

http://dx.doi.org/10.1046/j.1365-2648.2000.01567.x

Huffner, T. 2007. The BPM maturity model - towards a framework for assessing the business process management maturity of organisations: Master thesis. University of Karlsruhe, Norderstedt, Germany.

Humphrey, W. 1988. Characterizing the software process: a maturity framework, IEEE Software 2(5): 73-79. http://dx.doi.org/10.1109/52.2014

Hung, R. Y. Y. 2006. Business process management as competitive advantage: a review and empirical study, Total Quality Management \& Business Excellence 17(1): 21-40.

http://dx.doi.org/10.1080/14783360500249836

Jaklic, J.; Trkman, P.; Groynik, A.; Stemberger, M. 2006. Enhancing lean supply chain maturity with business process management, Journal of Information and Organizational Sciences 30(2): 205-223.

Janjic, V.; Todorovic, M.; Jovanovic, D. 2015. A comparative analysis of modern performance measurement and management models of companies, Economic Themes 53(2): 303-318.

http://dx.doi.org/10.1515/ethemes-2015-0017

Kothari, C. R. 2003. Research methodology: methods and techniques. New Delhi: Wishwa Prakashan.

Landeta, J. 2006. Current validity of the Delphi method in social sciences, Technological Forecasting and Social Change 73(5): 467-482. http://dx.doi.org/10.1016/j.techfore.2005.09.002

Lee, J.; Lee, D.; Kang, S. 2007. An overview of the business process maturity model (BPMM), Chapter 42 in K. C. Chang, W. Wang, L. Chen, C. A. Ellis, C. H. Hsu, A. C. Tsoi, H. Wang, X. Lin, Y. Yang, J. Xu (Eds.). Advances in Web and Network Technologies, and Information Management, Berlin, Germany: Springer. http://dx.doi.org/10.1007/978-3-540-72909-9_42

Lindemulder, M. J. 2015. Development of a continuous improvement maturity model assessment instrument [online], [cited 15 December 2015]. Available from Internet: http://essay.utwente. nl/67322/1/Lindemulder_BA_BMS.pdf

Lockamy, A.; McCormack, K. 2004. The development of a supply chain management process maturity model using the concepts of business process orientation, Supply Chain Management: an International Journal 9(4): 272-278. http://dx.doi.org/10.1108/13598540410550019

Maull, S.; Tranfield, D.; Maull, W. 2003. Factors characterising the maturity of BPR programmes, International Journal of Operations \& Production Management 23(6): 596-624.

http://dx.doi.org/10.1108/01443570310476645

McCormack, K.; Johnson, W. C. 2002. Supply chain networks and business process orientation: advanced strategies and best practices. Miami, Florida: CRC Press.

http://dx.doi.org/10.1201/9781420000344

McCormack, K.; Ladeira, M. B.; de Oliveira, M. P. V. 2008. Supply chain maturity and performance in Brazil, Supply Chain Management: an International Journal 13(4): 272-282.

http://dx.doi.org/10.1108/13598540810882161 
McCormack, K. et al. 2009. A global investigation of key turning points in business process maturity, Business Process Management Journal 15(5): 792-815.

http://dx.doi.org/10.1108/14637150910987946

Netland, T. H.; Alfnes, E.; Fauske, H. 2007. How mature is your supply chain? A supply chain maturity assessment test, in 14th International EurOMA Conference Managing Operations in an Expanding Europe (EurOMA 2007), 17-20 June, 2007, Ankara, Turkey.

Neubauer, T. 2009. An empirical study about the status of business process management, Business Process Management Journal 15(2): 166-183. http://dx.doi.org/10.1108/14637150910949434

Palmberg, K. 2010. Experiences of implementing process management: a multiple-case study, Business Process Management Journal 16(1): 93-113. http://dx.doi.org/10.1108/14637151011017967

Radosavljevic, M. 2015. Process orientation as a basis for increasing supply chain management maturity, Economic Themes 53(3): 407-423. http://dx.doi.org/10.1515/ethemes-2015-0023

Röglinger, M.; Pöppelbuß, J.; Becker, J. 2012. Maturity models in business process management, Business Process Management Journal 18(2): 328-346.

Rosemann, M.; De Bruin, T. 2005. Application of a holistic model for determining BPM maturity, BPTrends 2: 1-21.

Rosemann, M.; Vom Brocke, J. 2015. The six core elements of business process management, Chapter 5 in M. Rosemann, J. Vom Brocke (Eds.). Handbook on business process management 1, Berlin, Germany: Springer. http://dx.doi.org/10.1007/978-3-642-45100-3_5

Sommerville, I.; Ransom, J. 2005. An empirical study of industrial requirements engineering process assessment and improvement, ACM Transactions on Software Engineering and Methodology 14(1): 85-117. http://dx.doi.org/10.1145/1044834.1044837

Van Looy, A.; De Backer, M.; Poels, G. 2011. Defining business process maturity: a journey towards excellence, Total Quality Management \& Business Excellence 22(11): 1119-1137.

Vaidyanathan, K.; Howell, G. 2007. Construction supply chain maturity model-conceptual framework, in 15th IGLC Conference Lean Construction: A New Paradigm for Managing Capital Projects, 15 July, 2007, Michigan, USA.

Van Landeghem, R.; Persoons, K. 2001. Benchmarking of logistical operations based on a causal model, International Journal of Operations \& Production Management 21(1/2): 254-267.

http://dx.doi.org/10.1108/01443570110358576

Wu, Z.; Christensen, D.; Li, M.; Wang, Q. 2006. A survey of CMM/CMMI implementation in China, Chapter 41 in M. Li, B. Boehm, L. Osterweil (Eds.). Unifying the software process spectrum, Berlin, Germany: Springer. http://dx.doi.org/10.1007/11608035_41

Zairi, M.; Ahmed, P. K. 1999. Benchmarking maturity as we approach the millennium?, Total Quality Management 10(4-5): 810-816. http://dx.doi.org/10.1080/0954412997848 
Marija RADOSAVLJEVIC is an Associate Professor and vice-dean for the science at the Faculty of Economics, University of Nis, for narrow scientific field Business Management and a Visiting Professor at Willamette University, Atkinson Graduate School of Management, Oregon, USA. She graduated in 2001 at the Faculty of Economic in Nis, as a student of generation. As a student, she won few prizes, among them prize of town Nis and University of Nis. She has participated in few projects, financed by Ministry of Science of Republic of Serbia. Master and doctoral thesis she defended at the Faculty of Economics in Belgrade in 2004 and 2009, respectively. Three times she was engaged as a researcher at the University for Economics and Business Administration, Department for Production Management, Wien, Austria. Her key interest areas are: quality management, process management, cost management. So far, she has published more than 130 papers in journals and proceedings from the conferences (national and international) and 4 monographs.

Nada BARAC is Full Professor at Faculty of Economics, University of Nis. She is member of the following professional bodies: Society of Economists in Serbia and The European Association for Education and Research in Commercial Distribution. She has participated in five projects which were financed by The Government of the Republic of Serbia and also was a researcher on project 149052 that was financed by Ministry of Science and Environment Protection RS: 2005-2010 and on international projects - TEMPUS Project CD_JEP 17019 - 2002, TEMPUS Project CD_JEP_41103 - 2006, TEMPUS Project CD_JEP 41146 - 2006. Her foreign countries experience includes: LSE London UK, 1985, Otto-von-Guericke-Universität Magdeburg, Lehrstuhl Logistik, IFSL TU Dresden, Fakultät Maschinenwesen Institut für Fördertechnik, Baumaschinen und Logistik TU München, Faculty of Mechanical Engineering, Faculty of Mechanical Engineering (Department of Material Handling, Material Flow and Logistics), Master of science "International business development" JEP_41103_2006 (Liste des members du consortium groupe ecole superieure de commerce de Clermont- ${ }^{-}$CI Clermont- FD/ Issoire, France). She has written more than 250 papers, and more than 10 books and monographs.

Vesna JANKOVIC-MILIC is an Assistant Professor and vice-dean for the finance at the Faculty of Economics, University of Nis, for narrow scientific field of Economic statistics, the application of mathematical and statistical methods in economic research. The MSc degree she gained at the Faculty of Economics, University of Belgrade and $\mathrm{PhD}$ degree at the Faculty of Economics, University of Nis. She has published three monographs as well as many papers in scientific and professional journals and has participated in research conferences at home and abroad. She worked as a researcher on projects funded by the Ministry of Education and Science of Republic of Serbia. She participated in numerous seminars and professional training abroad.

Aleksandra ANDJELKOVIC is an Assistant Professor at the Faculty of Economics, University of Nis, for narrow scientific field of Business management. She graduated in 2007 at the Faculty of Economic in Nis. She gained her PhD degree in 2014 at the Faculty of Ecconomics, University of Nis. Her key interest areas are: strategic management of logistics, international logistics, supply chains, international marketing, and marketing channels. So far, she has published more than 40 papers in journals and proceedings from the conferences (national and international). 